Vol. 2, No. 1 (2021):57-68

http://journalsttcipanas.ac.id/index.php/NPTRS/

p-ISSN 2722-9726, e-ISSN 2722-9718

Published by Cipanas Theological Seminary

\title{
Yesus Sebagai Guru
}

\author{
Daniel Stefanus
}

Email: danielstefanus71@gmail.com

\begin{abstract}
Abstrak
Konsep Yesus sebagai guru merupakan gagasan penting dalam Injil-Injil. Meskipun demikian, pemahaman terhadap identitas Yesus sebagai guru dilihat terutama dalam pendekatan yang bersifat teologis atau biblis. Untuk itu, artikel ini berupaya untuk mengamati identitas dan karakter Yesus sebagai guru ditinjau dari sisi pedagogis. Tulisan akan membahas tiga aspek dari dimensi pelayanan Yesus sebagai guru, yakni, sebutan Yesus sebagai guru, pokok ajaran dan gaya mengajarNya.
\end{abstract}

Kata Kunci: Yesus, Guru, Pendidikan, Kerajaan Allah, Gaya Mengajar

\section{Sapaan Guru}

Biasanya kita menggambarkan Yesus dengan sebutan tang mutlak dan abstrak, yaitu sebagai Tuhan, Juru Selamat, Mesias, Putra Allah, Kepala Gereja atau lainnya. Itu tidak keliru. Tetapi keempat Kitab Injil menggambarkan Yesus dengan lebih konkret: Yesus adalah seorang guru.

Pekerjaan Yesus sebagai guru terutama digambarkan oleh Markus. Kitab injil Markus secara dramatis memberi kesan seolah-olah Tuhan Yesus telah menerus mengajar. Yesus, mengajar di Sinagoge, di tepai danau, di jalan, di bukit, di pantai, di pinggir sumur, di manamana. Markus 6:6 mencatat, "Yesus berjalan keliling dari desa ke desa sambil mengajar."

Yesus adalah seorang guru. ${ }^{1}$ Bahkan Pheme perkins menegaskan bahwa Yesus adalah seorang guru yang karismatik. ${ }^{2}$ Paling sedikit tampaknya ada enam bukti yang menunjukkan bahwa Yesus adalah seorang guru. Adapun keenam bukti tersebut adalah sebagai berikut:

\footnotetext{
${ }^{1}$ Gunther Bornkamm, Jesus of Nazareth (London: Hodder \& Stoughton, 1960), 57.

2 Pheme Perkins, Jesus as Teacher (New York: Cambridge University Press, 1990), 24.
} 
Vol. 2, No. 1 (2021):57-68

http://journalsttcipanas.ac.id/index.php/NPTRS/

p-ISSN 2722-9726, e-ISSN 2722-9718

Published by Cipanas Theological Seminary

1. Sebutan yang paling banyak digunakan untuk Yesus dalam keempat Injil adalah didaskalos, rabi dan rabuni. Sebutan didaskalos digunakan 42 kali dalam keempat kitab injil. Sebutan rabi 12 kali dan rabuni 2 kali. $^{3}$ Didaskalos adalah kata Yunani yang berarti guru. Rabi dan Rabuni adalah kata Ibrani dan Aram yang juga berarti guru. Sapaan "rabi" bukan hanya sapaan pertama yang didengar Yesus pada awal pelayanan-Nya, melainkan juga sapaan pertama yang didengar-Nya setelah kebangkitan-Nya.

2. Yesus sendiri menyebut diri-Nya guru (lih. Mat. 23:38; Mrk. 14:14; Luk. 22:11; Yoh. $13: 13-14)$

3. Terlihat jelas dimana kegiatan Yesus lebih sering digambarkankan dengan kata kerja "memberitakan" atau "berkhotbah." Kata kerja didaskō mengajar) dalam berbagai bentuknya telah dipakai 9 kali dalam Matius, 15 kali dalam Markus dan Lukas, dan 8 kali dalam Yohanes. Mengajar adalah pekerjaan Tuhan Yesus yang utama. Memang Ia kerap kali berkhotbah, menyembuhkan orang sakit dan melakukan mukjizat, namun kegiatanNya yang paling utama adalah mengajar. Apa yang disebut khotbah Tuhan Yesus sebenarnya bukanlah khotbah, melainkan pengajaran di mana pendengar boleh menginterupsi dengan pertanyaan atau sanggahan. Yesus sendiri sering menginterupsi pengajaran-Nya untuk bertanya dan menguji para pendengar.

4. Yesus sangat mementingkan pekerjaan mengajar. Misalnya, dalam Markus 9 dicatat bahwa Yesus tidak mau diitemui atau diganggu orang karena Ia sedang mengajar.

5. Yesus tidak hanya disebut rabi oleh para murid-Nya tetapi juga disebut rabi oleh para musuh-Nya (lih. Mrk. 12:14). Yesus disapa sebagai seorang rabi oleh karena nampaknya Ia pernah dididik dalam sekolah yang mempersiapkan bakal rabi.

6. Di rumah ibadat Nazaret Ia dihormati sebagai seorang rabi pengunjung (lih. Luk. 4:16-21).

\section{Isi Ajaran Yesus}

Isi ajaran Yesus adalah tentang Kerajaan Allah, diri-Nya sendiri, kematian-Nya dan masa yang akan datang. ${ }^{4}$ Sementara itu. T. W. Manson menyatakan bahwa isi ajaran Yesus

\footnotetext{
${ }^{3}$ Andar Ismail, Selamat Menabur: 33 Renungan Tentang Didik-Mendidik (Jakarta: BPK, 1997), 47.

${ }^{4}$ A. M. Hunter, The Work and the Word of Jesus (London: SCM, 1950), 111.
} 
Vol. 2, No. 1 (2021):57-68

http://journalsttcipanas.ac.id/index.php/NPTRS/

p-ISSN 2722-9726, e-ISSN 2722-9718

Published by Cipanas Theological Seminary

adalah Allah sebagai Bapa dan Allah sebagai Raja. ${ }^{5}$ Namun tema utama pengajaran-Nya adalah kerajaan Allah. Dalam Injil Markus istilah Kerajaan Allah terdapat 4 kali dan Kerajaan Sorga terdapat 33 kali.

Kerajaan Sorga atau Kerajaan Allah sama artinya. Kerajaan Sorga diutamakan penginjil Matius karena orang-orang Yahudi yang setia agak segan mengucapkan nama Allah. Matius berusaha menjauhkan diri dari penggunaan istilah yang dapat menginggung perasaan orangorang Yahudi untuk siapa Injilnya itu dimaksudkan. Ketiga penginjil lainnya, khususnya Markus dan Lukas memakai istilah "Kerajaan Allah" karena injil mereka ditujukan kepada orang-orang bukan Yahudi. Kata Aram yang dipakai oleh Yesus untuk Kerajaan Allah adalah malkuth. Artinya pemerintahan (aktivitas) seorang raja. Jadi, dapat dikatakan bahwa Yesus berbicara tentang pemerintahan (aktivitas) Allah sebagai Raja dan bukan wilayah kekuasaanNya. ${ }^{6}$ Andar Ismail menyatakan bahwa istilah malkuth bukan menggambarkan tempat atau wilayah dalam artian yang statis, melainkan menggambarkan kewibawaan atau tindakan dalam arti yang dinamis. ${ }^{7}$

Menurut pengajaran Yesus terdapat enam sifat Kerajaan Allah. Pertama, Kerajaan Allah sudah ada. Berbagai perumpamaan menunukkan bahwa menurut Yesus Kerajaan Allah bukanlah sebuah suasana hati dan bukan pula pengharapan untuk hari depan, melainkan sebuah tindakan Allah untuk memulai sebuah babak baru dalam sejarah, yang sudah dimulai dan sudah terjadi sejak sekarang ini. Sewaktu Yesus mengajar, Ia menegur para pendengar-Nya agar jangan jauh-jauh mencari Kerajaan itu karena Kerajaan Sorga sudah ada di antara mereka (lih. Luk. 17:21), yaitu dalam diri Yesus sendiri. Kerajaan Allah hadir dalam diri Yesus dalam tindakan-tindakan Yesus, misalnya: orang buta melihat, orang lumpuh berjalan, orang kusta menjadi tahir, orang tuli mendengar, orang mati dibangkitkan, setan diusir dan kepada orang miskin diberitakan kabar baik (lih. Mat. 11:5; Luk. 11:20). Kedua, Kerajaan Allah harus diambut secara pribadi. Jadi, Kerajaan Allah itu mempunyai dimensi kekiniaan yang berlaku pada setiap saat bagi orang-orang yang hidup (lih. Mrk. 10:15). Ketiga, Kerajaan Allah bersifat bertumbuh. Kerajaan Allah digambarkan sebagai sesuatu yang kecil tetapi secara diam-diam

\footnotetext{
${ }^{5}$ T.W. Manson, The Teaching of Jesus (London: Cambridge University Press, 1963), 141.

${ }^{6}$ John Drane, Introducing the New Testament (Lion, 1950), 113.

${ }^{7}$ Andar Ismail, Selamat Berkiprah: 33 Renungan Tentang Kesaksian (Jakarta: BPK, 2001), 60.
} 
Vol. 2, No. 1 (2021):57-68

http://journalsttcipanas.ac.id/index.php/NPTRS/

p-ISSN 2722-9726, e-ISSN 2722-9718

Published by Cipanas Theological Seminary

sedang bertumbuh. Contohnya adalah perumpamaan tentang penabur di Markus 4:3-8, tentang benih di Markus 4:26-29, tentang biji sesawi di Markus 4:30-32 dan tentang ragi di Lukas 13:20-21. Dalam semua contoh itu, Kerajaan Allah digambarkan sebagai sesuatu yang kecil tetapi secara diam-diam sedang bertumbuh. Itulah Kerajaan Allah. Ia datang melalui pekerjaan Yesus yang kecil-kecilan, namun tanpa gembar-gembor ia sedang bertumbuh. Keempat, kehidupan Kerajaan Allah seperti yang diajarkan Yesus bukanlah kesempatan untuk bermalasmalasan sambil menikmatinya. Apabila orang-orang tidak bertindak sebagai warga-warga yang bertanggung jawab maka "kewarganegaraan" mereka dapat dicabut dan diberikan kepada orang lain (lih. Mat. 21:43). Kelima, Kerajaan Allah bersifat masa yang akan datang. Kerajaan Allah dalam segala kelimpahannya adalah sesuatu yang masih harus kita nantikan kedatangannya pada suatu saat di masa yang akan datang. Yesus menyuruh para murid-Nya berdoa, "Bapa kami yang di sorga ... datanglah kerajaan-Mu ... (lih. Mat. 6:9-10). Keenam, Allah yang membuat dan mendatangkan Kerajaan Allah bukan kita.

\section{Gaya mengajar Yesus}

Yesus sebagai seorang guru memiliki berbagai gaya mengajar yang mampu menarik perhatian khalayak ramai (lih. Mrk. 1:22; 12:37). Adapun gaya mengajar Yesus adalah sebagai berikut:

1. Ceramah

Dengan metoda ceramah Yesus berusaha menyampaikan pengetahuan kepada muridmurid-Nya atau menafsirkan pengetahuan tersebut. Boechlke menegaskan bahwa melalui ceramah Yesus mengharapkan dua respons dari para pendengar-Nya, yakni: pengertian mendalam dan perilaku baru. ${ }^{8}$

2. Bimbingan

Yesus mengajar juga melalui bimbingan. Dalam Matius 10 misalnya, kedua belas murid telah menerima petunjuk-petunjuk dari Yesus untuk mengusir roh-roh jahat, melenyapkan segala penyakit dan memberitakan bahwa Kerajaan Sorga sudah dekat.

3. Menghafalkan

\footnotetext{
${ }^{8}$ Robert R. Boehlke, Sejarah Perkembangan Pikiran Dan Praktek Pendidikan Agama Kristen Dari Plato Sampai IG. Loyola (Jakarta: BPK, 2009), 66.
} 
Vol. 2, No. 1 (2021):57-68

http://journalsttcipanas.ac.id/index.php/NPTRS/

p-ISSN 2722-9726, e-ISSN 2722-9718

Published by Cipanas Theological Seminary

Setelah Yesus mengajarkan sesuatu atau selama Ia mengajarkan sesuatu, Yesus sering mengikhtisarkan isinya dalam ucapan yang gampang dihafal, misalnya saja, “... Anak Manusia adalah Tuhan atas hari Sabat" (Mat. 12:8), "Bukan orang sehat yang memerlukan tabib, tetapi orang sakit” (Mat. 9:12), “Anak Manusia juga datang bukan untuk dilayani, malainkan untuk melayani dan untuk memberikan nyawanya menjadi tebusan bagi banyak orang (Mrk. 10:45).

4. Pewujudan

Gaya mengajar "pewujudan" merupakan pendekatan khas Matius terhadap pelayanan Yesus. Tuhan Yesus dilukiskan sebagai seorang yang telah mewujudkan dalam diri pribadiNya sebagian dari sejarah bangsa israel. Ia, sama halnya seperti keturunan Yakub, turun ke Mesir agar diloloskan dari bahaya. Kemudian, Yesus pun adalah yang dipanggil keluar dari Mesir (lih. Mat. 2:13-15). Lalu ada masa pencobaan di padang gurun yang sejajar dengan pengalaman bangsa Israel di Sinai (lih. Mat. 4:1-11). Perwujudan lebih mendalam artinya dari pada hanya teknik memainkan peran, sebab teknik memainkan peran hanya berlaku untuk waktu sementara saja. Sedangkan dengan perwujudan Yesus mengajarkan kepada murid-murid-Nya bahwa diri pribadi-Nya adalah penyataan yang baru itu.

5. Dialog

Gaya mengajar dialog yang dilakukan Yesus banyak sekali contohnya dalam keempat Injil (misalnya saja: Mat. 19:16-26; Yoh. 4). Yesus sering mengajukan pertanyaan yang baru sebagai tanggapan-Nya atas pernyataan yang sebelumnya diajukan kepada-Nya.

6. Studi Kasus

Perumpamaan yang diceritakan Yesus merupakan studi kasus. Oleh karena itu, gaya mengajar studi kasus tersebut juga gaya mengajar yang memakai perumpamaan. ${ }^{9}$ Dengan studi kasus, misalnya "Anak yang Hilang”, para pendengar-Nya didorong untuk memikirkan inti persoalan dan bagaimana memecahkannya.

7. Perjumpaaan

Gaya mengajar perjumpaan disebut juga gaya mengajar yang memakai pertanyaan. ${ }^{10}$ Dengan gaya mengajar perjumpaan, para pelajar ditantang secara langsung untuk

\footnotetext{
${ }^{9}$ Boehlke, 68.

${ }^{10}$ Boehlke, 69.
} 
Vol. 2, No. 1 (2021):57-68

http://journalsttcipanas.ac.id/index.php/NPTRS/

p-ISSN 2722-9726, e-ISSN 2722-9718

Published by Cipanas Theological Seminary

mengambil keputusan. Di sini Yesus tidak bercerita. Ia memprakarsai pertanyaan yang pribadi dan besar sekali maknanya, misalnya, "Tetapi apa katamu, siapakah Aku ini?" (Mat. 16:15), “Diperbolehkankah menyembuhkan orang pada hari Sabat atau tidak?” (Luk. 14:3), “Percayakah engkau kepada Anak Manusia?” (Yoh. 9:35)

8. Perbuatan Simbolis

Dengan Yesus dibaptiskan oleh Yohanes Pembaptis pada awal pelayanan Yesus, Yesus ingin mengajar murid-murid-Nya melalui perbuatan simbolis ini. Pertama-tama Ia mengajarkan bahwa pelayan-Nya berarti perlunya pengorbanan diri sebagai tujuan utama kehidupan-Nya. Hubungan antara pengorbanan dan baptisan dinyatakan melalui jawabanNya kepada Yakobus dan Yohanes yang memohon agar mereka boleh menerima hak istimewa nanti. Kata Yesus, "Dapatkah kamu dibaptis dengan baptisan yang harus kuterima?" (Mrk. 10:38) Dalam hal ini baptisan-Nya merupakan lambang kesengsaraanNya nanti. Kedua, melalui lambang baptisan itu Yesus mengajarkan perlunya solider dengan semua orang. Contoh-contoh gaya mengajar simbolis yang lain dapat kita temui dalam peristiwa pertemuan Yesus dengan Zakheus (lih. Luk. 19:5) dan pembasuhan kaki para murid (lih. Yoh. 13:12-15). Selain itu, pemilihan kedua belas murid adalah perbuatan simbolis. Mengapa Yesus memanggil justru dua belas orang dan bukan sepuluh atau empat belas? Kedua belas orang itu melambangkan kedua belas anak-anak Yakub, dan artinya ialah bahwa Yesus sedang mendirikan Israel yang baru (lih. Mrk. 3:14-19).

9. Ucapan yang Berlebih-lebihan

Ucapan yang berlebih-lebihan digunakan untuk menonjolkan pesan secara mencolok. ${ }^{11}$ Selain itu, untuk mempertajam kebenaran tertentu di mana Yesus menitikberatkan sesuatu dengan jalan mengatakan sesuatu yang sebenarnya tidak boleh diterima secara harfiah. Ketika Yesus berkata, "Jikalau seorang datang kepada-Ku dan ia tidak membenci bapanya, ibunya, istrinya, anak-anaknya, saudara-saudaranya laki-laki atau perempuan, bahkan nyawanya sendiri, ia tidak dapat menjadi murid-Ku" (Luk. 14:26). Ia menitikberatkan fakta bahwa mengikut Dia, bukan sesuatu yang dapat dilakukan secara sambil lalu. Hubungan apa pun tidak boleh dianggap lebih penting dari pada pengabdian diri mereka pada Allah. Ketika Yesus menasihatkan tentang perlunya memenggal tangan atau kaku atau pun

\footnotetext{
${ }^{11}$ Andar Ismail, Selamat Mengikut Dia: 33 Renungan Tentang Kristus (Jakarta: BPK, 1994), 11.
} 
Vol. 2, No. 1 (2021):57-68

http://journalsttcipanas.ac.id/index.php/NPTRS/

p-ISSN 2722-9726, e-ISSN 2722-9718

Published by Cipanas Theological Seminary

mencungkil mata apabila masing-masing tangan atau kaki atau mata itu menyesatkan seseorang (lih. Mrk. 9:43-47). Ia bermaksud agar orang-orang memisahkan dirinya dari apa saja yang merupakan penghalang untuk mengiikut Dia.

10. Ucapan yang Berisi Permainan Kata

Yesus ahli sekali bermain dengan kata-kata, tetapi pendekatan semacam ini hanya dapat kita ketahui kalau kita mengerti bahasa Yesus, yaitu bahasa Aram. Ketika Ia mengecam kaum Farisi karena mereka sangat teliti dalam usaha menaati peraturan secara harfiah, semetara tidak menaruh perhatian terhadap keadilan, belas kasihan dan kesetiaan, maka Ia berkata, "Hai kamu pemimpin-pemimpin buta, nyamuk kamu tapiskan dari dalam minumanmu, tetapi unta yang didalamnya kamu telan" (Mat. 23:24). Dalam bahasa Aram, baik "nyamuk" maupun "unta", bunyi katanya hampir serupa, yaitu galma dan gamla sehingga Yesus mengatakan, "Hai kamu pemimpin-pemimpin buta, galma kamu tapiskan dari dalam minumanmu, tetapi gamla yang didalamnya kamu telan.”

Permainan kata lainnya kita temukan dalam ucapan terkenal Yesus yang dialamtkan kepada Petrus, "Engkau adalah Petrus dan di atas batu karang ini Aku akan mendirikan jemaat-Ku dan alam maut tidak akan menguasainya" (Mat. 16:18). Dalam bahasa Aram, baik batu maupun nama pribadi seseorang dinyatakan dengan kata yang sama, yaitu kefa. Oleh karena itu, Yesus mengatakan, "Engkau adalah Kefa dan di atas kefa ini Aku akan mendirikan jemaat-Ku dan alam maut tidak akan menguasainya.” Dengan permainan kata seperti itu Yesus berhasil menyampaikan amanat-Nya dengan cara yang segar dan menarik.

\section{Gaya Mengajar yang Memakai Tamsil}

kadang-kadang Yesus mengajar dengan jalan memakai suatu tamsil, misalnya saja, "Maka seperti lalang itu dikumpulkan dan dibakar dalam api, demikian juga pada akhir zaman" (Mat. 13:40) atau "Pada waktu itulah orang-orang benar akan bercahaya seperti matahari dalam Kerajaan Bapa mereka” (Mat. 13:43). Juga ayat yang sering dikutip oleh para pendidik digolongkan tamsil, yaitu, "Sesungguhnya barangsiapa tidak menyambut Kerajaan Allah seperti seorang anak kecil, ia tidak akan masuk ke dalamnya (mrk. 10:15). Dalam tamsil biasanya persamaan itu diperkenalkan melalui penggunaan kata: seperti, sebagai, sebagaimana.

12. Gaya Mengajar Memakai Kiasan atau Metafora 
Vol. 2, No. 1 (2021):57-68

http://journalsttcipanas.ac.id/index.php/NPTRS/

p-ISSN 2722-9726, e-ISSN 2722-9718

Published by Cipanas Theological Seminary

Dalam kiasan atau metafora persamaan antara dua gagasan atau keadaan ditunjukkan secara langsung tanpa memakai sesuatu kata perkenalan. ${ }^{12}$ Misalnya saja, menurut Matius 5:13 orang-orang yang percaya kepada Yesus tidak disamakan dengan garam, melainkan mereka adalah garam. Selain itu, dalam kecaman-Nya yang pedas terhadap kaum Farisi, mereka disebut ular dan bukan seperti ular.

13. Gaya Mengajar yang Memakai Bentuk Argumentasi "Jika ..., Apalagi ..."

Setelah Yesus menyatakan bahwa kesulitan bahkan penganiayaan akan merupakan bagian mereka Yesus berkata, "Cukuplah bagi seorang murid, jika ia menjadi sama seperti gurunya dan bagi seorang hamba jika ia menjadi sama seperti tuannya. jika tuan rumah disebut Beelzebul, apalagi seisi rumahnya" 9Mat. 10:25). Dalam pengajaran-Nya tentang berdoa, Yesus akhirnya menarik kesimpulan berdasarkan formula yang sama, yaitu: "jadi, jika kamu yang jahat tahu memberi pemberiaan yang baik kepada anak-anakmu, apalagi Bapamu yang di sorga!” (Luk.11:13a).

Tetapi kadang-kadang "jika” dan "apalagi” itu tersirat dalam kesimpulan. Misalnya saja, kepada para penentang-Nya yang tidak konsekuen yang mengecam Yesus menyembuhkan seorang perempuan pada hari Sabat, Yesus menegaskan: "Hai orang-orang munafik, bukankah setiap orang di antaramu melepaskan lembunya atau keledainya pada hari Sabat dari kandangnya dan membawanya ke tempat minuman? Bukankah perempuan ini, yang sudah delapan belas tahun diikat oleh Iblis, harus dilepaskan dari ikatannya itu, karena ia adalah keturunan Abraham?” (Luk. 13:15-16).

\section{Persejajaran yang Sinonimus}

Persejajaran yang sinonimus adalah gaya mengajar di mana baris atau kalimat pertama diucapkan ulang dengan kata yang sama dalam barus kedua. Contoh-contoh persejajaran yang sinonimus terdapat dalam Markus 3:24-25 yang berbunyi "Kalau suatu kerajaan terpecah belas, kerajaan itu tidak dapat bertahan, dan jika suatu rumah tangga itu tidak dapat bertahan "; Markus 4:22 yang berbunyi, "Sebab tidak ada sesuatu yang tersembunyi yang tidak akan dinyatakan, dan tidak ada sesuatu yang rahasia yang tidak akan tersingkap" dan Matius 7:7-8 yang berbunyi, "mintalah, maka akan diberikan kepadamu; carilah maka kamu akan mendapat; ketoklah, maka pintu akan dibukakan bagimu. Karena setiap orang

\footnotetext{
${ }^{12}$ Robert H. Stein, The Method and Message of Jesus's Teachings (Philadelphia: WJK, 1978), 16.
} 
Vol. 2, No. 1 (2021):57-68

http://journalsttcipanas.ac.id/index.php/NPTRS/

p-ISSN 2722-9726, e-ISSN 2722-9718

Published by Cipanas Theological Seminary

yang meminta, menerima dan setiap orang yang mencari akan mendapat, dan setiap orang yang mengetok, baginya puntu dibukakan."

Dalam kutipan dari Markus 3 dan 4 di atas, kita dapat melihat bagaimana baris kedua itu menitikberatkan gagasan yang sama yang disampaikan melalui baris pertama, tetapi dengan kata-kata yang berlebihan. Melalui teknik itu artinya menjadi semakin jelas. Kutipan dari Matius 7, bentuknya berbeda, bukan satu baris yang mengulangi lagi gagasan pokok dalam baris pertama, melainkan dua baris yang fungsinya sama, yaitu kata kerja "carilah" dan "ketoklah" yang artinya tidak begitu berbeda dari inti kata yang pertama, yakni "mintalah.” Baris yang paling kahir merupakan rangkuman dari keseluruhannya.

15. Persejajaran yang Antitesis

Dalam persejajaran yang antitesis baris yang kedua bertentangan dengan yang pertama sehingga gagasan pokoknya semakin nyata. Contoh-contoh persejajaran yang antitesis terdapat dalam Markus 8:35 yang berbunyi, "Karena siapa yang mau menyelamatkan nyawanya, ia akan kehilangan nyawanya, tetapi barangsiapa kehilangan nyawanya karena Aku dan karena Injil, ia akan menyelamatkannya"; Lukas 6:21a yang berbunyi, "Berbahagialah, hai kamu yang sekarang ini lapar karena kamu akan dipuaskan"; Lukas 6:25a yang berbunyi, "Celakalah kamu yang sekarang ini kenyang, karena kamu akan lapar"; dalam Lukas 16:10 yang berbunyi, "Barangsiapa setia dalam perkara-perkara kecil, ia juga setia juga dalam perkara-perkara yang besar. Dan barangsiapa tidak benar dalam perkara-perkara kecil, ia tidak benar juga dalam perkara-perkara besar.”

16. Persejajaran yang Sintesis

Persejaran yang sintesis tidak mengulangi dalam baris kedua yang sudah tampak dalam baris pertama, juga tidak mempertentangkan baris kedua dengan baris pertama. Sebagai penggantinya, gagasan pokok dinyatakan dalam baris pertama, dan baris yang selanjutnya membangun di atasnya atau meneruskan gagasan yang sama sampai artinya semakin lengkap. Contoh persejajaran yang sintetis terdapat dalam Matius 23:5-7 yang berbunyi, "mereka memakai tali sembahyang yang lebar dan jumbai yang panjang; mereka suka duduk di tempat terhormat dalam perjamuan dan di tempat terdepan di rumah ibadat; mereka suka menerima penghormatan di pasar dan suka dipanggil Rabi.” Baris pertama menyampaikan gagasan pokok, yaitu: "Semua pekerjaan yang mereka lakukan hanya 
Vol. 2, No. 1 (2021):57-68

http://journalsttcipanas.ac.id/index.php/NPTRS/

p-ISSN 2722-9726, e-ISSN 2722-9718

Published by Cipanas Theological Seminary

dimaksud supaya dilihat orang." Lantas kita diberitahukan dengan cara bagaimana mereka bertindak supaya dilihat orang.

17. Persejajaran yang Klimaktis

Dalam persejajaran yang sintesis dan persejajaran yang klimaktis, baris kedua tidak mengurangi arti baris pertama, melainkan dalam baris kedua gagasan pokok dari baris pertama diperluas atau dikembangkan lebih lanjut. Tetapi dalam persejajaran yang klimaktis, gagasan pokok itu mencapai puncaknya dalam baris kedua. Boleh dikatakan bahwa baris kedua itu meningkatkan arti yang disebut dalam baris pertama. contoh-contoh persejajaran yang klimaktis terdapat dalam Markus 9:37 yang berbunyi, "Barangsiapa menyambut seorang anak seperti ini dalam nama-Ku, ia menyambut Aku. Dan barangsiapa menyambut Aku, bukan Aku yang disambutnya, tetapi Dia yang mengutus Aku"; dalam Natius 5:17 yang berbunyi, "Janganlah kamu menyangka, bahwa Aku datang untuk meniadakan hukum Taurat atau kitab para nabi. Aku datang bukan untuk meniadakannya, melainkan untuk menggenapinya."

18. Gaya Mengajar yang Memakai Ucapan Peribahasa

Kadang-kadang Yesus mengajar dengan memakai ucapan peribahasa, misalnya, "Ikutlah Aku dan biarlah orang-orang mati menguburkan orang-orang mati mereka” (Mat. 8:22) atau "Setiap orang yang siap membajak tetapi menoleh ke belakang, tidak layak untuk kerajaan Allah" (Lukas 9:62). Ucapan Yesus yang terdapat dalam Matius 8:22 sebenarnya berasal dari peribahasa Ibrani yang berbunyi, "seperti membiarkan orang mati menguburkan orang mati." Perbuatan itu berarti perbuatan yang tidak bertanggung jawab sebab dalam masyarakat Yahudi mengurus pemakaman merupakan tanggung jawab keluarga dan komunitas. Melakukan pemakaman secara baik dinilai penting.

Tuhan Yesus sebagai anggota komunitas Yahudi tahu betul adat yang berlaku, yakni menguburkan orang meninggal adalah perkara yang sangat penting. Namun, Yesus berkata, 'Ikutlah Aku dan biarlah orang-orang mati menguburkan orang-orang mati." Maksud Yesus adalah menguburkan orang mati adalah sangat penting tetapi mengikut Yesus adalah jauh lebih pentiing lagi. Dengan perkataan lain, mengikut Yesus adalah lebih penting lagi. Dengan perkataan lain, mengikut Yesus adalah urusan yang lebih penting dari urusan yang 


\section{The New Perspective in Theology and Religious Studies}

Vol. 2, No. 1 (2021):57-68

http://journalsttcipanas.ac.id/index.php/NPTRS/

p-ISSN 2722-9726, e-ISSN 2722-9718

Published by Cipanas Theological Seminary

paling penting, yakni menguburkan jenazah ayahnya. ${ }^{13}$ Jadi, di sini Yesus sama sekali bukan bermaksud agar orang itu menelantarkan pemakaman ayahnya. Di sini Yesus menekankan tingginya nilai mengikut Dia.

Ucapan Yesus yang terdapat dalam Lukas 9:26 pun termasuk ucapan peribahasa. Pada zaman itu, ada peribahasa Ibrani yang berbunyi, "seperti orang membajak dan menoleh ke belakang”, artinya melakukan sesuatu tidak dengan separuh hati. Dengan mennggunakan peribahasa itu, Yesus menanggapi orang yang berkata, “Aku akan mengikut Engkau, Tuhan, tetapi ijinkanlah aku pamitan dahulu dengan keluargaku” (Luk. 9:61). Di sini Yesus bukan melarang orang itu berpamitan. Di sini Yesus ingin menegaskan mengikut Yesus bukan perbuatan yang bisa dilakukan setengah-setengah. Dengan perkataan lain, Yesus menekankan kesungguhan hati dalam mengikut Dia.

\section{Kesimpulan}

Gaya mengajar Yesus yang demikian banyak dan luar biasa tersebut memiliki sumbangsih yang amat berarti bagi model pendidikan di Indonesia. Para pendidik dapat belajar untuk selalu menambah perbendaharaan gaya mengajarnya. Seorang guru juga diharapkan untuk lebih kreatif dalam menciptakan gaya mengajar yang baru. Yang terakhir, seorang pengajar perlu memiliki sebuah model mengajar yang unik, khas dan istimewa.

\section{Daftar Pustaka}

Boehlke, Robert R. Sejarah Perkembangan Pikiran Dan Praktek Pendidikan Agama Kristen Dari Plato Sampai IG. Loyola. Jakarta: BPK, 2009.

Bornkamm, Gunther. Jesus of Nazareth. London: Hodder \& Stoughton, 1960.

Drane, John. Introducing the New Testament. Lion, 1950.

Hunter, A. M. The Work and the Word of Jesus. London: SCM, 1950.

Ismail, Andar. Selamat Berkiprah: 33 Renungan Tentang Kesaksian. Jakarta: BPK, 2001.

—. Selamat Menabur: 33 Renungan Tentang Didik-Mendidik. Jakarta: BPK, 1997.

—. Selamat Mengikut Dia: 33 Renungan Tentang Kristus. Jakarta: BPK, 1994.

\footnotetext{
${ }^{13}$ Ismail, Selamat Mengikut Dia: 33 Renungan Tentang Kristus, 9.
} 
Vol. 2, No. 1 (2021):57-68

http://journalsttcipanas.ac.id/index.php/NPTRS/

p-ISSN 2722-9726, e-ISSN 2722-9718

Published by Cipanas Theological Seminary

Manson, T.W. The Teaching of Jesus. London: Cambridge University Press, 1963.

Perkins, Pheme. Jesus as Teacher. New York: Cambridge University Press, 1990.

Stein, Robert H. The Method and Message of Jesus's Teachings. Philadelphia: WJK, 1978. 